\title{
A Voz Contra a Guerra na Obra do Operário Anarquista Santos Barbosa
}

\section{*Cássia Ferreira Miranda}

\begin{abstract}
Resumo
O presente artigo discute parte da produção literária e dramatúrgica do operário anarquista Santos Barbosa, analisando um conto e um prólogo dramático de sua autoria intitulados A Volta..... Os textos foram publicados no jornal pelotense O Rebate ao longo do ano de 1915. Através da análise dessas obras é possível perceber a importância que foi dada no meio operário ao debate relacionado à Primeira Guerra Mundial e aos seus efeitos devastadores. Santos Barbosa apresenta nesses textos diferentes argumentos relacionados à guerra e demonstra interesse em defender os preceitos anarquistas como a repulsa ao governo, ao capitalismo, à figura de deus e à pátria, que envia jovens inocentes a guerras despropositais. Esse trabalho tem por base metodológica a perspectiva da História Cultural, e desta forma, empreender uma narrativa histórica através de fontes literárias e dramatúrgicas.
\end{abstract}

Palavras-chave: literatura e dramaturgia operári - anarquismo - primeira guerra mundial Santos Barbosa

\begin{abstract}
This paper discusses part of the worker anarchist Santos Barbosa's production, analyzing a short story and a dramatic prologue of his own entitled A Volta.... The texts were published in the Pelotas's newspaper O Rebate throughout the year 1915. From the analysis of these works it is possible to acknowledge the importance that the workers had given to the debate concerning the First World War and its devastating effects. In his texts, Santos Barbosa presents several arguments concerning the war and shows interest in the defense of anarchists's precepts such as the revulsion of government, capitalism, the figure of the god and the country, which sends young innocent men to pointless wars. This paper is based on the methodological perspective of Cultural History, and thus undertakes a historical narrative from literary and dramaturgical sources.
\end{abstract}

keywords: worker's literature and dramaturgy - anarchism - first world war - Santos Barbosa 
A década de 1910 foi um período de grande atividade política entre os operários, principalmente aqueles adeptos à ideologia anarquista ${ }^{1}$. Entre as diversas ações que foram executadas pelos militantes operários anarquistas a fim de lutar contra as péssimas condições que viviam, encontram-se o teatro, a poesia e a imprensa. Os textos teatrais e/ou literários traziam as tensões, os sentimentos e os anseios do trabalhador dedicado à mudança social. O estudo das manifestações artísticas e literárias do operariado permite localizar os temas e as preocupações sócio-políticas que estavam no cotidiano dos trabalhadores do período. Por meio da análise dramatúrgica e literária de suas obras operárias é possível, pela perspectiva da Nova História Cultural, adentrar no universo desses militantes anarquistas. O uso desse tipo de fonte possibilita à história o testemunho do olhar dos trabalhadores organizados. Conforme destaca Sevcenko (2003), a literatura de determinado grupo traz:

a revelação de seus "focos mais candentes de tensão e a mágoa dos aflitos" trazendo "no seu âmago mais um anseio de mudança do que os mecanismos da permanecia". Nesse sentido' a escrita literária feita pelos operários' fornece uma leitura da expectativa do seu "vir"āser" (p. 29).

Os jornais são uma importante fonte de pesquisa na qual se encontra parte da produção operária. Nas páginas dos periódicos operários do período era possível acompanhar as atividades operárias e textos escritos pelos trabalhadores militantes. Contos, diálogos, poesias e peças de teatro estão presentes nessas publicações. A imprensa libertária teve papel de destaque na militância operária, e, assim como o teatro social ${ }^{2}$, despontou como um elemento cultural poderoso, visando a educação, a informação, o congraçamento e a mobilização operária. Conforme indica Rodrigues (1992), "o teatro anarquista no Brasil, ao longo de sua existência, de quase meio século, realizou uma excelente obra de alcance ideológico que pôs em prática o sentimento de solidariedade humana" (p.57).

Um operário que demostra ter se dedicado intensamente à arte engajada, tanto ao teatro social quanto à literatura, foi Joaquim Francisco Santos Barbosa. Geralmente referenciado como Santos Barbosa, ou ainda sob seu pseudônimo Saint-Barb, o militante anarquista, de local e data de nascimento desconhecidos, cuja profissão era pintor, atuou intensamente na política e na arte libertária. No Rio de Janeiro (RJ), em 1913, participou da criação do Grupo Dramático Cultura Social e em Pelotas (RS), em 1914, da criação do Grupo Teatral Cultura Social. Além dessas atividades, Santos Barbosa também se dedicou à escrita de diálogos, contos, poemas, canções e peças, sem descartar a grande quantidade de conferências realizadas. Os anos de 1914 e, especialmente, 1915 foram muito férteis no que diz respeito à escrita do operário Santos Barbosa. Isso se confirma pelas diversas publicações que ele fez nos jornais pelotenses O Rebate e A Luta, e no jornal carioca A Voz do Trabalhador ${ }^{3}$. As produções literárias de Santos Barbosa refletem a dimensão do conhecimento e engajamento desse operário. Entre os diversos textos escritos por Santos Barbosa destacam-se as peças Famintos, $A$ Volta..., O Homem das Bombas, Pamonha e Comp., Amores de Crianças, A Recompensa, Na Barricada, Os Renegados e $O$ Notivago ${ }^{4}$; e os contos Tuberculoso..., Maio!..., A Recompensa, Por uma madrugada e A Volta....

Em 1915, Santos Barbosa publicou no jornal O Rebate o conto e o prólogo dramático A Volta... Em plena Primeira Guerra Mundial, esses textos mostram os sofrimentos que a guerra traz para a humanidade, refletindo a preocupação do autor com a violência desenfreada e sem propósito decorrentes dessa guerra. Nesse mesmo contexto, denunciam a manipulação dos dirigentes que, por ganância, enviam jovens para o fronte de batalha, desestruturando famílias operárias, condenando jovens à morte, deixando mulheres viúvas, e mães e pais desamparados.

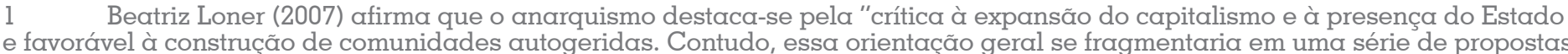
e tendências, algumas delas dando maior ênfase à educação, outras à violência ou ao isolamento em comunidades próprias e algumas apostando na via sindical. O sindicalismo revolucionário reuniria as ideias socialistas e anarquistas, propondo o sindicato como grande instrumento de luta dos trabalhadores, defendendo a luta de classes, a açấo direta dos trabalhadores e a manutenção da autonomia. Teria uma perspectiva de longo prazo de construção de uma sociedade gerida pelos trabalhadores através dos sindicatos. Como esse devia se manter autônomo e independente das correntes eu seu interior, isso permitia o trabalho comum de várias tendências, cada uma pondo a ênfase no setor que mais lhe conviesse - educação, cultura ou sindicalismo - motivo da generalizada utilização do termo anarquismo para referir-se a ele" (p. 514).

Forma como era mencionado, nos jornais operários, o tipo de teatro feito pelos anarquistas. Assim, o teatro social era visto 2 Forma como era mencionado, nos jornais operă

3 Esses periódicos podem ser consultados na Bibliotheca Pública Pelotense, no Arquivo de Memória Operária do Rio de Janeiro (Universidade Federal do Rio de Janeiro) e no Arquivo Edgard Leuenroth (Universidade Estadual de Campinas). 


\section{Conto A Volta...}

O conto, tal como outras narrativas literárias similares, se destaca como sendo um episódio breve, tratando de uma única ação de maneira concisa, conforme frisa Newton Cunha (2003):

Do ponto de vista de sua composição' os recursos narrativos' como os diálogos' as descrições e as dissertações' recebem um tratamento sumário e concentrado Daí dizer'se que o conto é univalente' ou seja' dedica'se a um só conflito' a uma ação determinada' envolvendo poucos personagens' tratados necessariamente de maneira plana (p. 183).

As características centralizadoras do gênero condicionam essa forma literária a um número reduzido de personagens. Não há espaço para o desenvolvimento da complexidade das personagens, sendo que a ação fica centrada em uma personagem específica, com a qual, ou em relação a qual, ela ocorre. Por ser marcado pela sua concisão, o conto deve trazer à tona um momento significante na vida da personagem.

No conto $A$ Volta... o jovem Lourival retorna da guerra. Lourival é um rapaz de cabelos negros e crespos e com "voz de rebelde". Ele é recebido como um herói por populares que estavam a sua espera, na pobre e velha casa de sua tia Rita: uma estalagem extremamente humilde, pequena e sofrendo os desgastes do tempo. Com as palavras do conto: "Em todos aqueles semblantes plebeus esvoaçava uma alegria estranha, uma nova e singular satisfação". Toda a narrativa se passa nesse local, onde é realizado o discurso pelo jovem que voltava da guerra. O discurso do "herói" em cima de uma caixa, com a população inquieta se apertando no local para conseguir ouvi-lo, passa a ideia da simplicidade que permeia o meio operário, tornado o cenário semelhante à realidade vivida pelo leitor, que consegue mais facilmente se identificar com a história. Sem mais detalhamentos, portanto, a narração se limita à sala da casa de tia Rita. Não há referências cronológicas. No entanto, a história se passa com uma grande concentração de populares que aguardavam no local da ação, sendo provável que não tenha ocorrido em um dia de trabalho. O lapso temporal em que ocorre a narrativa é extremamente curto, pois a trama se inicia com um discurso, e acaba com a morte do discursante ainda em cima de seu "palanque". Lourival é ovacionado, todos querem ter contato com ele. Ele discursa, agradece e reforça que, embora emocionado, espera que os presentes nunca sejam aplaudidos por tal feito. Lourival aponta os aspectos cruéis da guerra e se posiciona totalmente contra ela e contra aqueles que se tornam soldados, denominados por ele de "profissionais da morte". Ele defende e exalta a anarquia, grita e conclama o povo a gritar com ele. Entre os gritos de "viva!" a anarquia, Lourival, que estava sobre um caixote, um pouco acima da população que o cercava, é alvo de um tiro, e cai "desamparadamente sobre as pessoas que o rodeavam".

No final do conto percebe-se que, ao ter contato com a guerra, Lourival começa a criticá-la, aderindo ao anarquismo. Lourival é apresentado por Santos Barbosa como herói por ter abdicado de atuar na guerra. A narrativa se centra mais na descrição que o jovem faz da guerra, reafirmando esperançoso e cheio de energia sua adesão ao anarquismo. Neste momento, quando ele descreve a guerra, salienta uma personagem que povoa seu imaginário: o soldado que sucumbe à barbárie.

Todas as personagens se apresentam muito acolhedoras e felizes pela chegada do rapaz. Sua tia, Rita, se abraçava nele e chorava, talvez por estar alegre ou, até mesmo, aliviada por Lourival ter conseguido retornar vivo pra casa. Há apenas uma personagem que destoa do clima fraternal e alegre compartilhado pelas outras. Esta personagem é descrita como um trabalhador enérgico e bastante indignado com as exaltações libertárias de Lourival. Este homem, exaltado, com um tiro, tira a vida do jovem rapaz.

\section{Prólogo dramático A Volta...}

O escrito dramatúrgico A Volta..., denominado por Santos Barbosa de prólogo dramático ${ }^{5}$, é dividido em duas cenas publicadas em quatro edições na coluna Social Teatro Popular, do jornal O Rebate, com diferença cronológica entre as publicações variando entre 11 e 14 dias, nos seguintes dias: 13 e 24 de julho, 7 e 20 de agosto de 1915. A diferença cronológica entre as publicações é variável, o que permite perceber que eram destinadas ao público que assinava o jornal ou o acompanhava diariamente.

A Volta... apresenta o seguinte enredo: um filho retorna para casa, onde seu pai, que estava dormindo, o

O termo prólogo dramático é usado aqui de acordo com o significado atribuído por Pavis (2008), se referindo a uma peça pequena e autônoma que se assemelha ao intermédio e a cortina, ou seja, formas curtas de dramatizações independentes. 
recebe surpreso. Ao ser questionado, o Filho conta para o Pai que desertou da guerra. Não reagindo bem à notícia e demonstrando sua contrariedade, o Pai, que se encontrava com a saúde debilitada, é agressivo e rejeita seu Filho, que, tentando o comover, relata as atrocidades vivenciadas nas trincheiras. Ouvem-se sons de fuzilaria, vozes apavoradas e em desespero com a guerra. O Pai volta a adormecer e o Filho angustiado acompanha a agitação exterior. Ocorrem duas cenas simultâneas: o Filho e o seu desespero pelo que ouve da rua, e o som da voz de um homem (Pedinchão - mendigo) criticando os jovens que vão acompanhar os soldados na guerra. Das ruas o som tumultuado chega para o jovem Filho desesperado. O Pedinchão bate na porta e o Filho o deixa entrar. Ao ver que o rapaz regressara da guerra, Pedinchão se surpreende e o abraça alegre. Pedinchão confraterniza com o jovem que recusou a "arte de matar". O Pai acorda, mas está atordoado, confuso e muito fraco. Pedinchão se assusta com os barulhos vindos de fora do aposento e, de imediato, propõe que o jovem fuja, pois do contrário será preso como desertor. O Filho, hesitando, demonstra estar confuso e não ter certeza do que fazer. O Pai, agonizante, tenta deter o Filho. Não consegue, e morre. Diante do quadro de dor, Pedinchão assume uma postura de defesa com arma em punho. O Filho, amaldiçoando a guerra, cai prostrado sobre o corpo do pai. O Pedinchão percebe que a única atitude a ser tomada é enfrentar, e, corajosamente, avança para a porta e dispara sua arma.

Com relação aos aspectos espaciais, o cenário do prólogo é único, sendo indicado por Santos Barbosa como: "Aposento pobre. Cama à D.F. ${ }^{6}$ Caixote à cabeceira... Moringue e caneco. Tamborete á E.B. ${ }^{7}$ Arde um candieiro. Porta à E.F. ${ }^{8}$ ". Logo, toda a trama ocorre no mesmo ambiente, fazendo referência à parte externa quando se ouvem as vozes apavoradas por causa da guerra que ocorre na rua. A existência de poucos objetos em cena é justificada pela fala do Pai, na qual informa ter vendido alguns objetos para comprar comida, visto que, estando doente e com seu filho ausente, não tinha como se sustentar.

A questão temporal pode ser entendida como um período relativamente curto, visto que ocorre entre o momento que o jovem retorna e é recebido pelo Pai - que se revolta com ele e adormece - e o momento em que o Pedinchão entra - acorda o Pai que, logo após, morre nos braços do Filho - e acaba tendo que enfrentar o inevitável confronto com a guerra. É possível supor que a ação se passa à noite, por três motivos: há a indicação do candeeiro aceso, o Pai estava dormindo quando o Filho regressa, e o Pedinchão antes de entrar em cena, ao dialogar com as vozes da rua, deseja "boa noite".

Na relação nominal das personagens, Santos Barbosa as identificou apenas pelo nome e idade: Pai - 60 anos; Filho - 25 anos; Pedinchão (mendigo) - 40 anos. Ele as denomina de "figuras" e não de personagens. Essa designação, no caso desse texto, é bastante pertinente, dentro do entendimento do que venha a ser uma "figura" num texto dramático.

A figura designa um tipo de personagem sem que seja precisado de que traços particulares essa personagem se compõe ['] A figura' como o papel e o tipo' reagrupa um conjunto de traços distintos bastante genéricos· Ela se apresenta como uma silhueta' uma massa ainda imprecisa ['] (PAVIS, 2008, p.167).

O Pai está elaborado a partir de um comportamento patriótico, capaz de qualquer sacrifício em nome da pátria. Tem a saúde debilitada pela cólera e temperamento explosivo. Rejeita o filho desertor, preferia ter um filho morto e herói de guerra. O Filho, que foi para a guerra pelos valores paternos, se rebela com os horrores que vivenciou. Ele diz ter regressado com "a alma despedaçada, o sangue nas veias e o coração dilacerado.... o cérebro numa vertigem de sangue e morte, o espírito atormentado...”. É o desertor que compreende que a guerra só destrói e maltrata, e apenas os ricos é que ganham com o embate entre irmãos. O Pedinchão tem por traço a ironia e a coragem. Ele atua como um marginal da sociedade, ou seja, um mendigo. Mas nem por isso deixa de compreender o verdadeiro sentido destrutivo da guerra. Essa característica de Pedinchão pode ser observada quando ele, fora da cena, antes de entrar na casa do Filho, dialoga com uma voz que representa um patriota:

\footnotetext{
Pendinchão 'fora' - Boa noite' onde vai você?

$1^{a} \mathrm{voz}$ - Vou em defesa da pátria!
}

\footnotetext{
Direita fundo: tendo como referência o olhar do espectador, lado direito do palco, ao fundo.

Esquerda baixa: tendo como referência o olhar do espectador, lado esquerdo do palco, à frente.

Esquerda fundo: tendo como referência o olhar do espectador, lado esquerdo do palco, ao fundo.
} 
Pedinchão (rindo' - Hás de ganhar muito com isso! Olha: deixa'te morrer pela pátria' porque ela te fará ressuscitar no dia seguinte!

1a voz 'afastando'se) - Vou cumprir o meu dever de jovem!

Pedinchão - Isso' isso! 'gargalha' Dá vida pelos outros' grande camelo! E depois da "ressurreição", vem falar'me de novo em humanidade e em deus' meu gaiato! 'gritando' Ó desmiolado sem coração e sem alma! Cabeça de taxo! Ó tu que de humano só tens a forma! Assassino!

Interessante observar que ao colocar a personagem do Pedinchão, Santos Barbosa dialoga com outros autores anarquistas ao trazer para as peças teatrais a figura do homem marginalizado, do excluído social. Conforme pode ser observado na compilação organizada por Maria Thereza Vargas, intitulada Antologia do Teatro Anarquista (2009), na qual a autora traz textos de Avelino Fóscolo, Marino Espagnolo e Pedro Catallo, com a representação de personagens que ficam perdidas, vagando pela escória de uma sociedade carregada de preconceitos. Essas personagens apontam para o sofrimento que a sociedade capitalista patrocinava: uma legião de pobres homens e mulheres desgarrados e ignorados.

Outro aspecto que pode ser observado na escrita de Santos Barbosa é a utilização frequente de didascálias. Segundo Ryngaert (1995), didascálias são indicações cênicas que auxiliam o leitor a compreender e imaginar a ação. Podem ser sugestões de ação ou descrições de cenário. Santos Barbosa demonstra se preocupar, durante a redação de seu texto, em deixar bem estabelecidos os acontecimentos e as intenções de suas personagens:

Pedinchão 'volta da porta' rápido' prevenido' atemorizado' - Chê! Ai vem uma escolta! Fuja! Ainda há tempo! Ligeiro! Cebo nas canelas! 'volta para a porta. O Filho' de pé aterrado' num desespero louco' quase a chorar' vacila'. Ande! Depressa! 'mantem'se em inquieta observação' ouve'se o rufar de tambores em tom de marcha' que se aproximam.

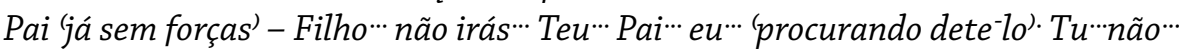

Filho 'desvairado' numa angustia máxima' - Meu pai?! Meu pai?!

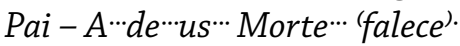

Como pode ser observado no fragmento acima, a construção dramatúrgica feita por Santos Barbosa faz uso de expressões coloquiais e regionalistas gaúchas que, provavelmente, faziam parte do cotidiano dos trabalhadores daquele período.

Quanto ao clímax de uma peça, David Ball (2009) afirma que ele é atingido quando "em algum ponto da peça, as mais importantes forças de conflito devem-se defrontar. Essa derradeira disputa resulta na restauração de um equilíbrio - seja o equilíbrio que deu início a peça, seja um novo equilíbrio" (p. 127). Em A Volta..., o clímax se dá no momento em que Pedinchão avista a escolta que se aproxima. Ele sabe o que isso significa. O jovem desertor será preso e, certamente, fuzilado por ter deixado o campo de batalha. Grita ao jovem para que fuja. Mas o jovem está atordoado e desesperado com o pai agonizante e que acaba, nesse momento desesperante, morrendo. O jovem desesperado, amaldiçoando a pátria, cai debruçado sobre o corpo do seu pai. O pedinchão, diante do quadro de dor e morte, num ato de coragem e fúria suicida, se encaminha para a porta de saída e dispara a sua arma. Eis que se instaura uma nova estase, isto é, um equilíbrio. Após o choque final prevaleceram a violência, o sofrimento e a morte. Assim, cai o pano e termina a peça. O autor assina, datando a escrita do prólogo em novembro de 1914, e acrescenta que a peça era muito bem quista pelos operários: "Nota: Esta peça tem sido várias vezes e sempre com agrado geral, levada a cena no Teatro $1^{\mathrm{o}}$ de Maio, pelo G. T. Cultura Social. - S.B.”.

\section{Reverberações das "Voltas" de Santos Barbosa}

O universo temático trazido por Santos Barbosa em seus escritos permite perceber os temas que ele elegeu como importantes de serem debatidos. Ao escolher o tema que deseja tratar, o autor utiliza toda a estrutura do conto para desenvolvê-lo por meio da ação. Conforme Pavis (2008) destaca: "o tema geral é o resumo da ação ou do universo dramático, sua ideia central ou seu princípio organizador” (p. 399). 
Santos Barbosa retrata uma sociedade doente, que deixa seus homens e mulheres desempregados, excluídos, entregues à própria sorte, que manda jovens rapazes para guerras sem propósitos, que tem como desculpa para a ganância dos governantes a defesa da pátria. No conto A Volta... Lourival descreve os horrores a que são submetidos aqueles que são enviados para a guerra:

Lourival - No campo de batalha' pisando e queimando cadáveres de irmãos' cego de sangue e de morte; desvairado ao lúgubre som do clarim e do rufar dos tambores e as fúnebres vozes de comando; em face das emboscadas e ataques horriveis e rios de sangue que corre ou coagula pelos campos' mon' tes ou colinas; fuzilando' decapitando' esquartejando' trucidando seres iguais' e tudo isso em nome dessa coisa que chamam ` pátria! Do egoísmo dos poderosos e dos capitalistas; praticando tão cruéis barbaridades' o soldado mais justifica a perda dos sentimentos de homem que a caserna lhe rouba' gargalhando miseravelmente.

A responsabilidade sobre a guerra, que era muito combatida pelos anarquistas, caía sobre os governantes que a promoviam, mas não arriscavam sua vida por ela. Conforme é ressaltado no conto A Volta... era o povo, que nenhum interesse tinha por ela, que ia para as trincheiras. No prólogo dramático o rapaz a descreve detalhadamente:

Filho - Se os olhos vagassem por sobre o cenário tétrico e clamoroso duma batalha encarniçada; pelos montes de cadáveres que juncam extensões inteiras de fecundas terras feitas lagos de sangue fresco e coagulado' coberto de insetos daninhos; se por toda aquela região da morte se lhe deparas' sem corpos decompostos' carnes mutiladas' órgãos humanos desagregados' atirados à mercê acariciadora e trágica do tempo; gritos lancinantes' dores e arrependimentos; ' estou bem certo de que meu pai amaldiçoaria a pátria e os causadores do desperdício de tantas energias.

Observa-se que a postura tomada pelo pai, de rejeição ao seu filho, bate de frente com o ideal anarquista de repúdio à participação na guerra. Essa preocupação estava latente no período da escrita desse prólogo devido à Primeira Guerra Mundial. Nos jornais do período, com destaque para O Rebate, são constantes as reflexões sobre os absurdos da guerra e a luta contra o alistamento obrigatório. Indo de encontro às ideias libertárias, o pai representa um trabalhador alienado e manipulado.

Assim, nas obras de Santos Barbosa ocorre uma constante denúncia e crítica ao arbítrio daqueles que deveriam se dedicar a melhorias sociais. Todas essas diferentes abordagens dos detentores do poder vêm para reforçar uma temática muito defendida pelos anarquistas: o poder nunca é algo positivo, a sociedade não deve se organizar verticalmente. $\mathrm{O}$ anarquista Bakunin quando discorre a respeito da sociedade afirma que sua constituição:

Não [deveria ser] de cima para baixo e segundo algum plano ideal sonhado por alguns sábios eruditos' e menos ainda por decretos emanados de algum poder ditatorial' e menos ainda por uma assembleia nacional eleita por sufrágio universal. Como já demonstrei' um tal sistema levaria inevitavelmente à criação de um novo estado e' consequentemente' à formação de uma aristocracia oficial' isto é uma classe de individuos que não teriam nada em comum com o povo e que começariam imediatamente a explorar e subjugar esse povo em nome do bem estar geral ou para salvar o Estado ${ }^{(1986,} p^{\cdot 76)}$.

Um tema que também aparece no prólogo dramático A Volta... é a crítica àqueles que personificam os pilares da sociedade que promovem a guerra:

Filho - 'continuando' Essa malta desprezível de governantes' banqueiros' capitalistas e militarões' que arruinando tudo' devastando vidas e arrastando cidades' gozam assim o produto de suas am ${ }^{-}$ bições e caprichos loucos' conquistando territórios' esgotando "stocks", movimentando dinheiros' atirando os filhos do povo uns contra os outros' como verdadeiros seres sem coração e sem alma.

Nesse momento é possível observar que o autor também se aproxima da crítica anarquista ao monopólio das riquezas comuns, algo considerado inadmissível, visto que promovia as desigualdades e incenti- 
vava a violência. Errico Malatesta (1989) faz uma crítica ao capitalismo e destaca que:

Um dos pontos fundamentais do anarquismo é a abolição do monopólio da terra' das matérias' primas e dos instrumentos de trabalho' e' consequentemente' a abolição da exploração do trabalho alheio exercida pelos detentores dos meios de produção. Toda apropriação do trabalho alheio' tudo o que serve a um homem para viver sem dar à sociedade sua contribuição à produção' é um roubo' do ponto de vista anarquista e socialista.

Os proprietários' os capitalistas' roubaram do povo' pela fraude ou pela violência' a terra e todos os meios de produção' e como consequência deste roubo inicial podem subtrair dos trabalhadores' a cada dia' o produto de seu trabalho (p. 120).

Outro tema que habita essas histórias é a crítica à crença em deus. O jovem Lourival também cita deus, em seu discurso, no conto A Volta.... Grita, em meio aos que o assistem, que abomina, juntamente com a noção de pátria, a crença em um deus. Embora não se aprofunde no tema, o autor-operário cita em seus contos a religião e a figura de deus, sempre pejorativamente, como era costume dos anarquistas. Renunciando a crença em um ser supremo, o anarquista Bakunin (1986) destaca:

Já que nenhuma abstração existe por si só ou para si mesma' já que não tem pernas para andar' nem braços para criar' nem estomago para digerir as milhares de vítimas que lhe são dadas para que devore' torna'se óbvio que essa abstração religiosa e celestial' o próprio deus' representa na verdade os interesses muito positivos e reais de uma casta privilegiada' o clero ( $p .75)$.

Como é recorrente nos textos escritos por anarquistas, Santos Barbosa também traz o debate relacionado à religiosidade no prólogo dramático A Volta..., vista de maneira negativa:

Filho - 'de si para si' Quantas lágrimas de mãe queridas' filhos amados e noivas estremecidas' verti' das por culpa dos potentados! Quanta dor! Quanta miséria!* E querem que sejamos patriotas; que acreditemos num deus que dizem ser piedoso e onipotente' criador do mundo e da vida' do coração e do pensamento' do amor e da razão' e também do ódio' da perfídia' da desolação e da morte '.. sem que nos redima do flagelo! Não' não quero crer em deus! Não quero ser religioso nem patriota! 'numa viva transposição físico'fisionômica' Oh! A guerra! A sociedade! O povo!.*

Essa tendência de fazer referência direta ou indireta à figura de deus e também a de Cristo era muito comum em textos anarquistas, seja pela alusão ao "ritual" da paixão, seja pela referência às suas qualidades sacrificadoras. No livro de Souza (2003), intitulado O Mito Político no teatro Anarquista Brasileiro, é identificada a figura de Cristo em vários textos libertários. No entanto, os que foram analisados por Souza (2003) usam personagens anarquistas com qualidades muito semelhantes à abnegação de um mártir, que se sacrifica na luta em busca do ideal anárquico. Já no prólogo em análise, Pedinchão relaciona o morrer pela pátria - dos jovens que vão à guerra - com a morte de Cristo na cruz, dizendo à $1^{\mathrm{a}}$ voz que, já que ele dará a vida pela pátria, que aguarde que ela a ressuscite. Santos Barbosa, fazendo essa analogia, possivelmente intenta criticar a postura de abnegação semelhante a de Cristo, quando essa se associa a algo que não tem sentido, pois não há nobreza nem recompensa em lutar pelas riquezas e pela pátria. Logo, fica clara a postura anarquista de reconhecer o comportamento de Cristo como algo muito nobre desde que canalizado a uma boa causa. Assim, o sacrifício encontra apoio no bem comum, ao contrário da guerra, que ocorre visando o interesse de uma minoria que sequer se envolve na batalha.

Há, ainda, a presença do ideal de revolução anarquista. Os anarquistas defendiam a necessidade de uma reestruturação social. Nas palavras do anarquista Woodcock (1983):

Uma revolução moral' mais do que uma revolução política Uma revolução política' luta contra o estado e a propriedade de fora' uma revolução social trabalha dentro da sociedade má e vai minando suas bases ['] através da razão e' basicamente' através da persuasão e do exemplo (p. 206).

Quando no prólogo dramático $A$ Volta... o Pedinchão encontra o jovem desertor da guerra e tenta 
acalmá-lo enquanto ele se mostra fragilizado, o autor faz uma crítica, frequente entre os libertários, à atribuição distorcida dada ao sentido de legalidade e justiça. Embora nesse contexto assassinar não seja considerado um crime, pois é uma conduta amparada pela lei e pela necessidade de defesa da pátria, a situação seria bem diferente se fosse um assassinato em uma briga entre operários, por exemplo. O Pedinchão deixa claro sua posição: "um homem honrado é um homem honrado e um assassino legal é um assassino legal". Logo, essa personagem expõe a incoerência do estado bélico que pretende justificar a "desumanização" do homem, que se transforma em assassino apoiado pela "lei”, que se vê transformado em número, que precisa exterminar e/ou ser exterminado, independentemente de sua história, de seus sonhos, e de sua família. Esse texto apresenta uma defesa da deserção dos jovens ante uma guerra capitalista/imperialista, e, consequentemente, sem qualquer sentido para uma vida digna para os trabalhadores. O autor deixa claro que é preciso combater os que se deixam iludir pelo discurso de defesa da pátria e defender os que desejam realmente uma mudança social. Dessa forma, Santos Barbosa coloca o mendigo defendendo, mesmo que num gesto suicida, o jovem que desertou da guerra capitalista.

Todos esses temas são utilizados por Santos Barbosa visando trabalhar um conflito principal, que orienta essas narrativas. Uma parte muito importante no desenvolvimento de uma narrativa é a construção do conflito. O conflito é uma oposição de forças. Patrice Pavis (2008) afirma que

há conflito quando um sujeito 'qualquer que seja sua natureza exata', ao perseguir certo objeto 'amor' poder' ideal' é "enfrentado" em sua empreitada por outro sujeito 'uma personagem' um obstáculo psi' cológico ou moral’ Esta oposição se traduz então por um combate individual ou "filosófico" [‥] (p. 67).

Esse "combate" descrito por Pavis ocorre ao longo da ação e se constitui na maioria das vezes em seu ponto alto. Para a existência do conflito é necessário que exista a presença de alguma dificuldade para o desenvolvimento de algo, isto é, um obstáculo. O conflito central de A Volta..., tanto no conto quanto no prólogo dramático, é a oposição entre os governos gananciosos que promovem a guerra e os jovens que se tornam vítimas quando são levados à batalha sem propósito.

No conto Lourival defende fortemente sua posição de aversão à guerra. Ele que vivenciou as atrocidades, denuncia o obstáculo para a existência da civilização e da humanidade:

Lourival - Deixa de ser homem para ser soldado' deixa de ser gente para transformar'se num autồ mato' que se manifesta ignorantemente' atiçado pelos seus superiores hierárquicos' pela vontade dos governantes e dos homens de dinheiro!

Como solução para o conflito, o jovem encontra a resposta no anarquismo, afirmando sua repulsa a deus e à pátria. As palavras de Lourival, rejeitando a pátria e a guerra, abominando deus, aclamando e fazendo o povo aclamar a anarquia, representam uma ameaça.

Conforme é possível observar em suas "Voltas", Santos Barbosa retratava o cotidiano operário, construindo representações, simbologias referentes à situação operária. A utilização do teatro e da literatura como ferramenta social e ideológica conferiu à classe operária um sentido de "grupo", de "coletivo", na medida em que permitiu a visualização de todo o conjunto de características compartilhadas por seus membros. A utilização de um determinado símbolo tem o poder de criar, ilustrar e justificar um imaginário coletivo que legitima determinada ideia. Conforme afirma José Murilo de Carvalho (1990):

É por meio do imaginário que se podem atingir não só a cabeça mas' de modo especial' o coração' isto é as aspirações os medos e as esperanças de um povo 'É nele que as sociedades definem suas identidades e objetivos' definem seus inimigos' organizam seu passado' presente e futuro O imaginário social é constituído e se expressa por ideologias e utopias' sem dúvida' mas também - e é aqui que me interessa - por símbolos' alegorias' rituais' mitos (p. 10).

Logo, o imaginário trata de um conjunto de sinais que emergem da realidade vivenciada por determinado grupo. Cada período e cada grupo constroem seu imaginário, isto é, o conjunto de representações que dão sentido à sua realidade. O olhar sobre a literatura e a dramaturgia de Santos Barbosa torna possível um olhar sobre o universo que ele vivenciava e o qual ele desejava representar: o cotidiano dos trabalhadores, suas 
angústias e seus planos. Além disso, permite perceber características do público para o qual essa produção se destinava. A natureza compacta do conto e do prólogo dramático vem ao encontro da necessidade de um público leitor que não dispõe de muito tempo para leitura. Os trabalhadores do início do século XX estavam vivendo um período no qual a jornada de trabalho era intensa, chegando, em algumas fábricas, a quinze horas por dia (Hardman e Leonardi, 1991). Como era escasso o tempo destinado ao lazer e à instrução, os contos proporcionavam o acesso à literatura em um curto espaço de tempo. $\mathrm{O}$ oferecimento de uma leitura rápida e simples aos operários cansados do longo dia de trabalho foi a maneira encontrada por Santos Barbosa para que os trabalhadores tivessem acesso à cultura literária. Os contos publicados serviam, assim, como um excelente meio de entretenimento e propagação dos ideais anarquistas entre os operários leitores.

As produções literárias de Santos Barbosa refletem a dimensão do conhecimento e engajamento deste operário. Sua forma de escrita é intensa, repleta do uso da linguagem figurada, muitas vezes trazendo para a reflexão os sentimentos mais difíceis da vida operária, as vivências mais dolorosas. Embora suas personagens sejam pouco detalhadas, a intensidade e riqueza com que descreve o cenário faz com que o leitor/espectador consiga visualizar tudo o que é relatado. Suas personagens representam determinados grupos sociais. Estão presentes como resultados de uma estrutura social, seja na personagem de vilão, ou na personagem de vítima. Um aspecto frequente da literatura libertária anarquista é a representação maniqueísta das personagens presentes ou relacionados à ação principal da narrativa. Logo, nas obras de Santos Barbosa, o vilão está sempre representado pelo sistema capitalista e seus seguidores. Assim, a grande personagem ausente e responsável pela vida sofrida e miserável da população trabalhadora é a detentora da riqueza, a burguesia.

\section{Referências}

BAKUNIN, Michael. A Igreja e o Estado. In: WOODCOCK, George (org.). Os grandes escritos anarquistas. Porto Alegre: L\&PM, 1986. 4 ed. p. 75-80.

BALL, David. Para Trás e para frente: um guia para leitura de peças teatrais. São Paulo: Perspectiva, 2009. CARVALHO, José Murilo de. A formação das almas: o imaginário da República no Brasil. SP: Companhia das Letras, 1990.

CUNHA, Newton. Dicionário Sesc: a linguagem da cultura. São Paulo: Sesc São Paulo, 2003.

HARDMAN, Foot. LEONARDI, Victor. História da Indústria e do Trabalho no Brasil (das origens aos anos 20). São Paulo: Ática, 1991. 2. ed.

LONER, Beatriz Ana. O Movimento Operário. In: BOEIRA, Nelson; GOLIN, Tau (org.). História Geral do Rio Grande do Sul: República. Passo Fundo: Meritos Editora, 2007.

MALATESTA, Errico. Escritos Revolucionários. Tradução: Plínio Augusto Coêlho. São Paulo: Novos Tempos, 1989.

PAVIS, Patrice. Dicionário de Teatro. São Paulo. Perspectiva, 2008.

RODRIGUES, Edgar. O Anarquismo na escola, no teatro, na poesia. RJ. Ed.: Achiamé, 1992.

RYNGAERT, Jean-Pierre. Introdução à análise do teatro. São Paulo: Martins Fontes, 1995.

SEVCENKO, Nicolau. Literatura como missão: tensões sociais e criação cultural na Primeira República. São Paulo: Companhia das Letras, 2003. 2 ed.

SOUZA, Dimas Antônio de. O mito político no teatro anarquista brasileiro. Rio de Janeiro: Achiamé. 2003. VARGAS, Maria Thereza. Antologia do teatro anarquista. São Paulo: WMF Martins Fontes, 2009.

WOODCOCK, George. Anarquismo: Uma história das ideias e movimentos libertários. Porto Alegre: LP\&M, 1983.

Submetido em 12/10/2014

Aprovado em 22/08/2015 